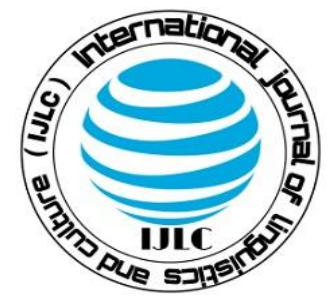
Volume \& Issues Obtainable at The Women University Multan
International Journal of Linguistics and Culture
ISSN (Print): 2707-6873, ISSN (Online): 2788-8347
Volume 2, No.1, June 2021
Journal homepage: http://ijlc.wum.edu.pk/index.php/ojs

\title{
A Critical Discourse Analysis of the River between by Ngugi Wa Thiang'o: Study of Gender Othering
}

\author{
Ghulam Yasin, \\ Lecturer, Department of English, Govt. Alamdar Hussain Islamia College, \\ Multan, Punjab, Pakistan, \\ E-mail: malikyasin83@gmail.com \\ Shaukat Ali, \\ Assistant. Professor, Govt. College Vehari, Punjab, Pakistan.
}

\begin{abstract}
The present research is a Critical Discourse Analysis of single postcolonial text The River Between by Ngugi (1965). It focuses to explore the discursive techniques employed in the selected text to propagate the concept of gendered Othering. Aim of the researcher is to find how the colonizers other the Kenyans by presenting their stereotypical representations in their discourse and how Ngugi unmasks the Whiteman's self-constructed ideologies about them. The researcher employs Van Dijk's (2004) analytical model to decode the text critically at words, phrases, sentences and discourse levels. The analytical devices adopted for the present research from this model are:' Actor description', 'categorization', 'lexicalization', 'authority', 'polarization' and 'metaphor'. Further linguistic devices included in the model are: 'repetition' and 'Absolute Term'. All these discursive techniques have been employed to decode the randomly selected data from the given text. The findings show that the theme of gendered othering is very dominant in the selected text and all the mentioned analytical devices have been frequently employed in the selected text to propagate the ideological representations of culture, gender and race.
\end{abstract}

Key Words: Gender, othering, postcolonial, Stereotype, woman

\section{Introduction}

The concept of 'Otherness' has ever been discussed by the philosophers, literary figures and linguists at the different levels. The term 'Othering' has been identified with the presence of another being and this other being is the binary opposition of the self. Generally speaking the other may be anyone 
who is opposite to the one`s self. The colonized subject is recognized as `other` through discourse by ascertaining the subjugation of the colonized people. Othering is basically the form social representation that is related with stereotypes. Different theories have been presented on othering which establish its relationship with gender, race and ethnicity. Othering may generally be termed as the marginalization of another person or group or by making them the other. The term 'othering was first of all introduced by Spivak in her well known essay "The Rani of Sirmur" (1985) She mentions it in the very opening lines of her essay: "How Europe had consolidated itself as sovereign subject by defining its colonies as 'Others,' even as it constituted them, for purposes of administration and the expansion of markets, in to programmed near-images of that very sovereign self" (p. 247). In reality the use of othering is a show of power relations. It occurs when 'we' begin to include ourselves in the group united in 'we', and the other group of people is considered and behaved as different or the opposite, further they are also united in 'they'. It means that the group of 'we' is making the show of his power. Now such differences are created on the basis of their culture, sex, gender and race.

\section{Gender based Othering}

De Beauvoir (1953) has described the concept of Othering on the basis of gender. She presents that the male dominated systems other the matriarchy on the grounds of their power. It is the dilemma of such societies that the dominated men consider them a 'center' and their women a 'margin'. Such women are considered to lack in norms and are identified only in relation to their men. Such type of social construct on the basis of gender develops our ideas about what it means to be a 'Man' or a 'Woman'. In literature and media discourse, a 'Man' is often presented with the positive characteristics as brave, ambitious, bold and confident being. On the other hand, a 'Woman' is portrayed quite contrary to this as weak, emotional, irrational and dependent on the men of her clan. So, according to De Beauvoir a binary opposition is created in this manner where the gender roles make one powerful or dominant over the other. Now, this powerful gender believes it a right to exercise the privileges over the weaker one and this type stereotypical representation of female gender may be observed in literature.

Johnson and Bankhead (2013) have studied the portrayal of female gender in African feminist writings. The Western discourse presents the black women and girls as ugly, uncultured and silenced slaves. The notion of beauty is directly connected with beauty of white skin and all other 
characteristics related to the white people. Such presentation of beauty constructs the complex of inferiority among the black women and makes them 'other'. It is mentioned: "Europeans' physical attributes have been and continue to be the yardstick for beauty in mainstream society. The beauty standard has created dichotomies as binary opposites to distinguish African features from European features such as kinky and straight, long and short, dark and light, good and bad" (p. 90). Such construction of beliefs has disturbed the psyche of many societies of the color. Beauty is being constructed socially and politically to emulate the dominant white community. The lacking of this constructed image of beauty has deep impact upon the lives of black women and it made them 'others'.

\section{Discourse Analysis}

Discourse analysis is a kind of method to find out how the units of speech larger than a sentence are combined together or structured to form a text. It is basically an analysis of the text on grammatical, lexical and stylistic grounds. Van Dijk (2006) mentions it: "We thus might want to examine the grammatical, stylistic, rhetorical, pragmatic, argumentative, interactional or other structures that define the various dimensions or levels of this speech. We might call this the central task of discourse and conversation analysis" (p. 160).

\section{Critical Discourse Analysis}

According to Fairclough (1992) Crictical Discourse Analysis is the study that finds out the relationship between language and power. According to him CDA observes discourse as a kind of social practice. Language is always connected with the social realities and is the cause of bringing some social change.

The basic goal of CDA is to deconstruct the ideologies entrenched in the discourse. Such embedded ideology produces and reproduces the asymmetrical power relationships in the society. The unbalanced power relationships between 'Us' and 'Them' or among the colonizers and the colonized is the major theme in postcolonial literature. According to Van Dijk (2004) "Groups may more or less control other groups or only control them in specific situations or social domains". This sort of control further becomes the laws or traditions and also seems natural to the dominated groups and further takes the shape "of what Gramsci called 'hegemony'. Class domination, sexism and racism are characteristic examples of such hegemony" (p. 355) It brings forth the view that power can be 
exercised and supremacy is attained not only through repression and subjugation, but it may also be maintained by the use of convincing potential of some discourse. In this way the basic purpose of $\mathrm{CDA}$ is to find out the ways of domination and asymmetrical power relationships embedded in the texts, either it is in written or spoken form.

In this kind of research, the critical discourse analysts show very clear position, and are desired to bring out and eventually to resist this sort of social inequality. Thus CDA is the kind of method that is chosen to expose the possible ideological, cultural and political meanings hidden or rooted in the text. Van Dijk (2004) has described the given questions and CDA helps in finding out their answers.

a- "How do (more) powerful groups control public discourse"?

b- "How does such discourse control mind and action of (less) powerful groups, and what are the social effects of such control, such as social disparity"? (p. 355)

\section{Socio-Cognitive Approach by Van Dijk}

Van Dijk (2006) considers discourse as an event of communication. According to him, discourse analysis is chiefly an analysis of the ideology and this analysis occurs at the levels of society, cognition and discourse. In this regard Social analysis is to observe the societal structures or the context of a text as a whole. Cognitive analysis deals with the social and personal cognition that mediates between society and discourse. Social cognition is the structure that describes the mental representations and processes of the members of a social group. Rashidi (2010) remarks; "The socio-cognitive model by van Dijk is based on the assumptions that cognition mediates between society and discourse. Both long-term and short term memories as well as certain mental models shape our perception and comprehension of discursive practices and also imply stereotypes and prejudices" (p. 58). Now the purpose of CDA is to examine the historical, political and social background of any discourse that describes the power relationships. It chiefly consists of two levels. One is the micro level that deals with language, discourse, verbal interaction. Second is the macro level that describes the power relationships and ideological representation. Van Dijk (2006) believes that the contextual approaches "generally assume a more or less direct relationship between situational, societal, political or cultural aspects of the environment of text and talk, on the one hand, and the structures of discourse itself, on the other" (p. 161). In van Dijk`s (2004) analytical approach, 
two major strategies may be found, positive demonstration of the 'Self' and negative illustration of the 'Other'. This manifestation of the binary opposition assists to examine Othering embedded in an ideological discourse.

\section{Data collection and Sampling Strategy}

In this research, textual analysis has been used as the method of data collection. Textual analysis is one of the fundamental strategies in qualitative research for collecting data. The sentences and chunks from the selected text dealing with the concept of gendered Othering have been selected by utilizing the purposive sampling strategy. This sort of sampling technique is used with keeping an explicit purpose in mind. It is also regarded as judgmental, selective or subjective sampling. It depends upon the judgment or selection of the researcher how he collects the data or chunks of the sample text for the purpose of further analysis.

\section{Conceptual Framework}

Van Dijk`s analytical framework (2004) is a specific and suitable framework that provides the researcher with tools of critical discourse analysis to find out the ideological concepts. It is also very suitable for this kind of research because Othering is an ideology and according to Van Dijk critical discourse analysis is also an ideological analysis. Further, this framework does provide the different discursive devices and such devices are the valid parameters to analyze the sample text in order to examine the concepts like Othering. In this regard Van Dijk (2004) has recommended two key discursive strategies in the shape of an 'ideological square':

a) "Emphasize 'Our' good things \& De-emphasize 'Their' good things"

b) "De-emphasize 'Our' bad things \& Emphasize 'Their' bad things". (p. 18)

\section{The Choice of Analytical devices}

Rashidi (2010) mentions that Van Dijk has used different analytical devices in this model (2004) and these are: “Actor description, 'categorization', 'lexicalization', 'disclaimer', 'irony', 'authority', 'polarization', 'metaphor', 'comparison', 'generalization', 'number game', 'self glorification' and hyperbole". (p. 59) Some linguistic devices added and used by the researcher in this particular research are 'repetition and absolute Term'. All the given devices in the selected are not relevant to the sample text being used for this particular research. In this way, the researcher has selected the 
relevant devices and has also included the couple of linguistic devices as per need of the research. The selected devices are mentioned in the table given below.

\section{Table 01}

\begin{tabular}{|l|l|}
\hline $\begin{array}{l}\text { Discursive devices selected from the analytical } \\
\text { model }\end{array}$ & $\begin{array}{l}\text { Linguistic devices added by the } \\
\text { Researcher }\end{array}$ \\
\hline $\begin{array}{l}\text { Authority, Actor Description, } \\
\text { Lexicalization, Categorization, } \\
\text { Polarization, Metaphor }\end{array}$ & repetition, Absolute term, \\
& \\
\hline
\end{tabular}

\section{Explanation of Discursive Devices Used in the Research}

- Actor Description: The positive and negative characteristics are described with the characters relating to 'US' and 'Them' or 'other' respectively. The presentations of attributes are shown through actors of the discourse.

- Authority: An author or a speaker reveals some references of well known experts to strengthen the arguments. It adds to authority of his opinions.

- Categorization: To classify the characters into "in-group and out-group" on the basis of their religion, culture and gender etc is known as categorization.

- Lexicalization: Particular lexical or vocabulary items are used knowingly by the author to convey some specific traditions and beliefs of some social group.

- Metaphor: Some metaphors are important in ideological presentation like 'US' are shown through positive metaphors, while negative metaphors are used for 'Them`.

- Polarization: The device employed to present the contrary traits to 'Us' and 'Them' in a discourse. Again it is employed by a narrator or an author.

- Repetition: it is a linguistic device to show the repetition of words, phrases or some expression in more than one time in a discourse.

- Absolute Terms: Absolute means perfect and the use of such words those fall in the group of absolute words in a discourse to show perfection like perfect, principal, supreme, all etc. 


\section{Data Analysis}

The researcher has done both the thematic and quantitative analysis of the selected sample data. For this purpose, the researcher has adopted van Dijk`s analytical model (2004) to find out the discursive techniques employed by the author of the sample text to propagate the desired ideology. The researcher has decoded the textual chunks in qualitative analysis to observe the selected analytical devices discussed in the modified model. The thematic analysis of the selected text has been done in details to describe the gender othering. However, the frequency of devices has been described through quantitative analysis in the form of a given table. This analysis shows only the data taken from the selected text.

\section{Frequency of the Analytical Devices used in the Selected Text}

\begin{tabular}{|l|l|l|}
\hline Analytical Devices & No of Use & Percentage \\
\hline Actor Description & 37 & 38.14 \\
\hline Categorization & 13 & 13.40 \\
\hline Lexicalization & 14 & 14.43 \\
\hline Metaphor & 04 & 4.12 \\
\hline Authority & 02 & 2.06 \\
\hline Polarization & 09 & 9.27 \\
\hline Repetition & 08 & 8.24 \\
\hline Absolute term & 07 & 7.21 \\
\hline Us-Them & 03 & 3.09 \\
\hline Total & 97 & 100 \\
\hline
\end{tabular}






Figure 01

\section{2: Column Chart}

The upper given column chart describes the number of presences of the analytical devices embedded in the selected text of "The River Between"

The table-01 and Column chart show that the author has used 97 analytical devices in the selected text to present the theme of gendered othering. This quantitative analysis presents that writer has used Actor Description for the most of time (37) than all other devices. Secondly, the device Lexicalization has been embedded 14 times and the lesser use of all is Authority (only 02 times). 


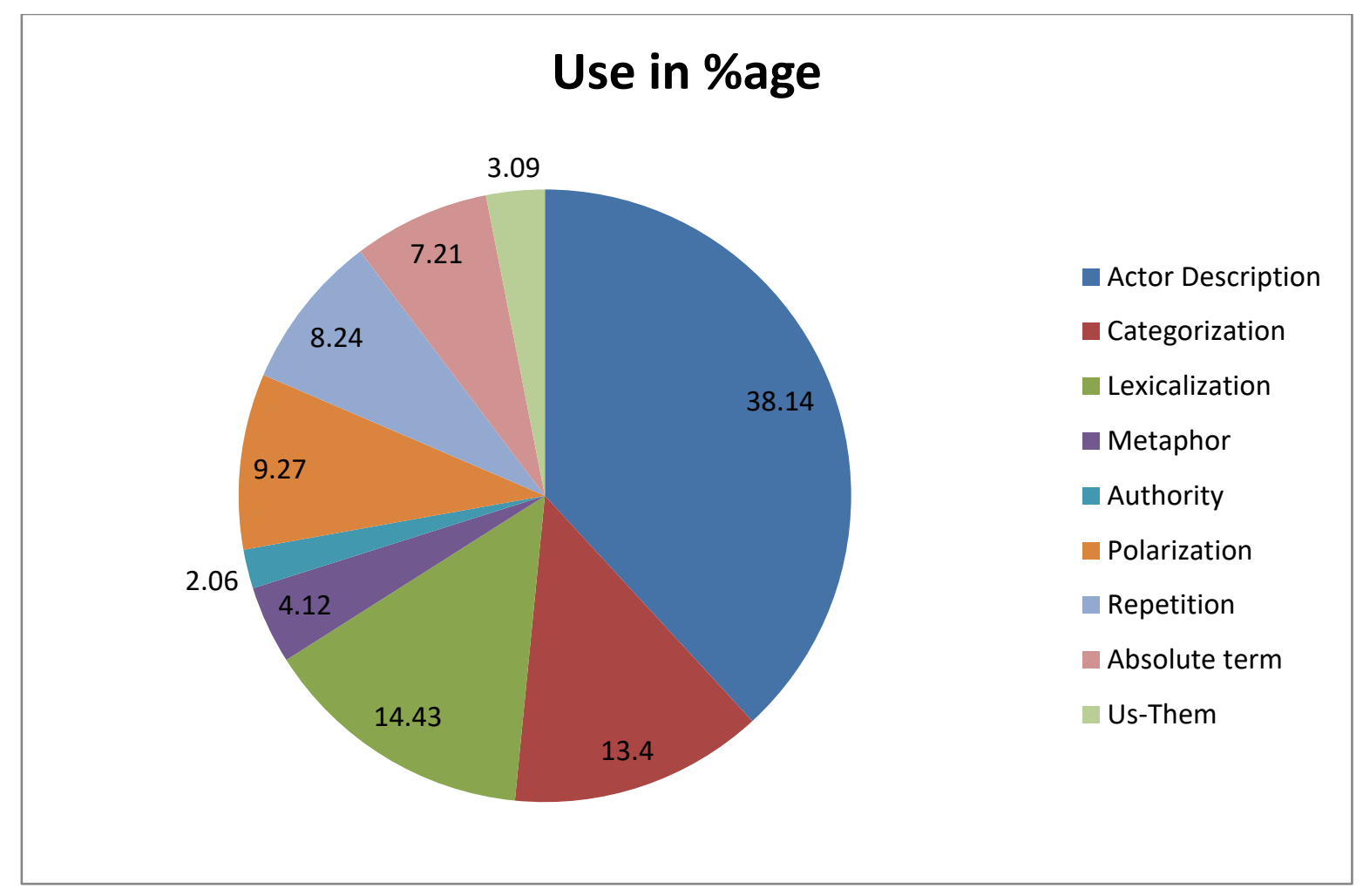

Figure 02

\subsection{Pie Chart}

The pie chart (figure 02) shows presents the frequency of presences of the analytical devices embedded in the selected text of "The River Between"

The upper given table-01 and figure 02 show the frequency in percentage of using analytical devices embedded in the text by the writer to present the theme of gendered othering. This analysis presents that writer has dominantly used Actor Description (38.14\%) and the lesser use of authority (02.06\%) as analytical devices in selected text to present the theme of gendered othering.

\section{Gendered Othering in the Novel "The River Between"}

'Gendered othering' is one of the most important subjects in postcolonial fictions and in the selected novel as well. Particularly in African fiction, the woman is leading her life under the double colonization. Once she is suppressed by the white dominancy and secondly she is being exploited by the men of his family. This sort of double marginalization may be observed in the selected text of this novel. 
"Long ago women used to rule this land and its men. They were harsh and men began to rest their hard hand. So when all the women were pregnant men come together and overthrew them. Before this women owed everything. The animal you saw was their goat. But because the women could not manage them" (P.15).

\section{Analytic Devices}

$\begin{array}{ll}\text { Repetition } & \text { women, them } \\ \text { Actor description } & \text { women, men } \\ \text { Polarization } & \text { harsh, hard, pregnant }\end{array}$

\section{Analysis}

One of the myths discussed in the selected novel was the description of female dominancy over their male members. This myth shows that once the women were more dominant and than their men in the social set up of Kenya. It shows that power is dynamic. It changes from one pole to another with the passage of time and there is no fixation in the power relationships. If at one time 'self' is dominant and the 'other' is weak, there is a possibility that the time may change into vice versa. The 'other' may also come forward as powerful. The dominancy of women over their male members and all other things of their clan describe their absolute authority. It has been mentioned that the power makes corrupt and the absolute power corrupts absolutely. As a result, their women used their power in a negative manner and humiliated their men. Finally, it created resistance by men.

In the selected text, the use of pronoun is also ideological. Pronoun 'They' is being used for women that shows the element of othering linguistically. Chiefly this pronoun is used for the negative connotations like wild customs and ignorant others.

According to the myth everything belongs to their women being the owners. They were also masters of the resources like goats but could not keep control over them because of their pregnancy. It presents their physical weakness and a big hurdle on their way to move ahead freely. In this way the theme of gendered othering is embedded in the sample data.

"The goats ran away. They knew woman to be weak, so why should they fear them. It was then Waiyaki understood why his mother owned nothing"• (p.15) 


\section{Analytic Devices}

Categorization fear, weak

Actor description woman, the goats

\section{Analysis}

The goats are considered as the gentle pet animals. If such gentle animals cannot be controlled by the women then how they can control the other harsh things related to the life. In the selected text the goats symbolize all natural resources, it means female gender is a weaker gender and is unable to control the financial issues. So it demands something like strong being to run the affairs of life. It supports the view that man is born to govern and is responsible for necessities of the life. Even woman as being the weaker becomes dependant over the stronger. It is not only men but even the goats also realize that women are weak and there is no way to remain under their control.

Othering is directly concerned with power relationships. If female gender was dominant then male gender becomes 'other' for them. When the balance of power is shifted towards the male gender then othering also shifts towards the female gender. It is the story of gender othering.

\section{"She was content to follow whatever her father said was right. And she feared his anger".} (p. 26)

\section{Analytic Devices}

Metaphor his anger

Actor description her father, she,

Absolute terms whatever

\section{Analysis}

It shows a clear message that a woman (she) should be contented with what she is being provided by the male member. It is showing the picture of male authority. The major duty of the female gender is only to obey their men. Such women get more respect who obey their Men silently and remain pleased in the upcoming life. The expression 'feared his anger' presents that female 
gender is a passive gender. She is unable to resist and should fear by the anger of their men. It is a social construct in the patriarchal societies that the real man is one who shows arrogance and anger in his home. His control over the female gender manifests his manliness. In this manner, such dreadful social constructs other their women.

The same sort of fear of a girl by her father is also being presented in the next line:

"Please sister, don't tell. Don't tell Father". (p. 27)

\section{Analytic Devices}

Repetition don`t tell

Actor description sister, Father

\section{Analysis}

It shows that the relationship of a daughter with her father is filled with doubts and fears. Here a sister is requesting the other to keep things in secret and the father should not know about it. The repetition of words "don't tell" shows the intensity of her fright from her father. The word 'father' is written in capital word and capitalization here is also ideological. It shows the strength, control and dominancy of a male member in the four walls of his home. So the sample text describes male gender as 'negative other' who has created fear with his anger and is the sign of a tyrant authority for all the female gender.

"She had inherited this stubborn spirit from Joshua, a man who once made up his mind, was hard to deflect from his set purpose". (p. 27)

\section{Analytic Devices}

Actor description Joshua, her

Lexicalization stubborn, inherited, hard

\section{Analysis}

In the sample text Joshua is being presented a 'positive other' with the positive traits like showing determination and steadfastness towards his goals. This sort of stubbornness in his nature also 
describes his command to convince other people and finally other people surrender before his willfulness. Again the text interprets the male dominant ideology with his strong interpretations.

"Her faith and belief in God were coupled with her fear of Joshua". (P.34)

\title{
Analytic Devices
}

Actor description Joshua, her

\begin{abstract}
Analysis
Context shows that Miriamu, the wife of Joshua, has left his ideology after converting into new religion Christianity. Further the sample text presents that her real belief in God is related with Joshua. The faith and belief of a weak gender is also weak like her. She cannot remain resolute without the guidance being provided by her husband in the form strict warnings.
\end{abstract}

On the basis of gender othering, the female gender even doesn't have liberty to use the choice of her belief and religion. She is even unable to choose the religion other than the religion of her husband. She must follow the husband as her religion. Again Joshua representing the male gender is wiser in knowledge and authoritative. Her wife representing the female gender is weaker in knowledge and can neither speak nor raise question about religion before her husband.

"I tell you again you know where your daughter is .Go! Go out and look for her". (p.34)

\section{Analytic Devices}

$\begin{array}{ll}\text { Actor description } & \text { your daughter, you, } \\ \text { Authority } & \text { I } \\ \text { Repetition } & \text { Go }\end{array}$

\section{Analysis}

The sample text starts with the first person pronoun 'I'. This expression shows the element of supremacy and authority of the speaker. The second Pronoun "you" tells the opposite expression that excludes 'the listener' from in group. The discourse also narrates inferior position and status of the listener. In fact the male member 'Joshua' is saying forcefully and also with certain authority 
that her wife 'You' surely knows where their daughter has gone at this time. The mother is being humiliated because of the action of a daughter only on the basis of gender. The repetition of the word "Go!" shows that the male gender is giving orders to the female gender for giving the exact information otherwise it may be ill for her. The element of antipathy and disrespect for the female gender (for both mother and daughter) is obvious. "Go out and look for her" is again the use of imperative structure and compels the female gender to obey the orders without any delay. It shows the supremacy of the male member who is going to marginalize the female members of the home. Female members are greater in number but they are being suppressed by their master of the home. This supremacy shows the element of gender othering.

"Our land is going slowly, taken from us, while we and our young men sit like women, watching"· (p.129)

\section{Analytic Devices}

Actor description we, young men

\section{Analysis}

The pronoun 'We' normally shows the connotation of harmony, unanimity and power. The sample text describes that Whiteman has got his supremacy in the areas of their clan. They are getting control over their resources and over their people. They are becoming an authority and marginalizing them in different affairs of life. They are being made slaves physically and mentally. They are coming under the rule of white supremacy. Secondly the phrase "We men and young men" describes that they are the men, they are the brave warriors, the future of their land depends upon their strength. As the binary opposition the women are idle and coward. The words "sit like women, watching" demonstrate the general ideology of the male dominated society. It is a general construct, the female gender can neither defend the country nor can do something constructive. It is a message that the men "we" have to act like men to defend their culture and native land. They should not behave idly like their women. There is generalization about the female gender that they physically weaker and cannot be equal to their men in every affair of life. They are being othered on the basis of gender. 


\section{Conclusion}

Analysis of the selected text on the basis of 'gendered othering' shows that the black woman in this novel has been described with a fixed identity. She is doubly marginalized. Once she is being contrasted with the White female on the basis of race, secondly, she is being marginalized with the social patriarchal set up physically and linguistically. There is a stereotypical representation of female gender either she is a mother or a daughter. The mother stands responsible for the actions of her children. The daughter is particularly being recognized with the attributes of her mother on the basis of gender. In the sample text the mother Miriamu is blamed for the decisions of her daughter Muthoni. Here, Mother is only a metaphor of sacrifice and responsibilities; every wrong doing being committed by the daughter is the cause of disgrace for the both, the daughter and mother. The Kenyan woman presented in the text owes nothing and has been presented as 'other' on the economic and social grounds. She is a weak, dependent and marginalized woman.

The researcher has used modified analytical framework based on Van Dijk's Socio-Cognitive Model (2004). The researcher has implied the analytical devices proposed by Van Dijk and has also added the couple of linguistic devices by considering it the need of text analysis. The author Ngugi has made the good use of these devices and may be frequently observed in the selected text. In fact these devices propagate the concept of binary opposition between 'Us' like African men with all positive characteristics and 'Them' like African women with bad attributes. In this way, these discursive devices have been used in the sample text to propagate the ideology of 'othering'.

\section{References}

Beauvoir, S. D. (1953). The Second Sex, trans. and ed. HM Parshley. London: Cape.

Dijk, T. A. (2000). Politics, ideology and discourse. Retrieved September 12, 2019, from http://www.discourse-in-society.org/teun.html

Dijk, T. A. (2001). 18 Critical discourse analysis. The handbook of discourse analysis, 349-371.

Dijk, T. A. (2004). Critical discourse analysis. Blackwell, Oxford , 352-371.

Dijk, T. A. (2006). Discourse, context and cognition. Sage Publications, 159-177.

Fairclough, N. (1992). Discourse and social change (Vol. 10). Cambridge: Polity press.

Johnson, T. A., \& Bankhead, T. (2013). Hair it is: Examining the experiences of Black women with natural hair. Open Journal of Social Sciences, 2014. 
Rashidi, N. (2010). A Critical Discourse Analysis Of The Debates Between Republicans And Democrats Over The Continuation Of War In Iraq . Jolie , 55-82.

Spivak, G. C. (1985). The Rani of Sirmur: An essay in reading the archives. History and Theory, 24(3), 247-272.

Wa, T. O. Ngugi. 1965. The River Between. Nairobi: Heinemann.

Widdowson, H. G. (2008). Text, context, pretext: Critical issues in discourse analysis (Vol. 12). John Wiley \& Sons. 